of Jalisco. This is an area of transition, of which very little is known to the anthropologist.

Dr. Beals has collected a mass of information on elements of culture which can be attributed definitely to tribal units or groups. From this evidence certain tentative inferences are drawn as to the cultural provinces of northern Mexico and an attempt is made to trace the influence of Middle America on the culture of the south-west and south-east of North America.

In the discussion of cultural provinces a large nonagricultural area in northern Mexico with a lack of pottery is defined. Further, it is shown that, at the time of the conquest, sub-Mexican cultures existed in Sinaloa (see above), while a culture of sub-Mexican or sub-Mayan type, utilising truncated stone-faced pyramids and stone or adobe architecture, was to be found about 200 miles from the Rio Grande in Tamaulipas. Continuous distributions for certain traits between Mexican cultures and the southwestern States are established, including stone and adobe architecture, the use of turquoise, idols, pottery and architecture. It was also discovered that there are a number of traits of similar distribution in the south-eastern States, northern Mexico and Middle America, such as the religious complex of altars, priests, perpetual fires, temples, temple mounds, and ceremonial trees, which suggests a definite connexion of the south-east with the region of higher culture in the south.

While recognising the influence of one area on another, it must also not be overlooked that very real development was made locally; for example, cultivation, after introduction from the south, was adapted to the local environment and dry-farming methods were developed.

\section{New Science Laboratories in Aligarh}

ATHOUGH Aligarh has been a centre of learn$A$ ing in India during the last sixty years, a new era has started with the erection of the new science laboratories for the Aligarh Muslim University. The laboratories are the fruits of the labours of Nawab Masood Jung Dr. S. R. Massod, the Vice-Chancellor of the University.

The laboratories for physics, chemistry, botany and zoology occupy separate blocks, each fitted with up-to-date appliances for research and advanced studies. To each of these laboratories is attached a library, having all the necessary and important scientific books and periodicals in English and other European languages.

Physical Laboratory: The Department of Physics is installed in a building consisting of about sixty rooms, in two blocks--one for teaching and the other for research and advanced studies. Prof. R. Samuel is the Nizam professor of physics and chairman of the Department; Dr. R. K. Asundi is reader in physics. The Department has been equipped with the following apparatus: Zeiss photometer, Zeiss three-prism glass spectrograph, Zeiss two-prism quartz spectrograph, two vacuum spectrographs, soft X-ray spectrograph, Zeiss comparator, Zeiss grating spectrograph, gratings, quartz spectrographs, quartz and glass monochromators, apparatus for electronic interference, etc.

At present there are some eighteen students working in the Laboratory on problems ranging from the study of absorption and emission spectra in the extreme ultra-violet, ultra-violet, visible and the infra-red region to problems of electronic interference, elećtronic diffraction, soft X-rays, photochemical problems, etc.

Chemical Laboratory: Prof. R. F. Hunter is Nizam professor of chemistry and chairman of the Depart. ment of Chemistry; Dr. R. D. Desai and Lt. M. Haider Khan are readers in chemistry.

Research work on the unsaturation and tauto. meric mobility of heterocyclic compounds, the electronic structure of organic perhalides and perhalide ions, and the lability of unshared electrons in organic compounds of different elements, is in progress. Arrangements have been made for the study of absorption spectra and dipole moments and polarisation of organic compounds as well.

Botanical Laboratory: The Department of Botany is under Dr. R. A. Khan, who has recently returned from Cambridge.

Special arrangements have been made for the study of problems in plant physiology. Facilities are given for research in every branch of botany and a botanical garden is attached to the Department. A museum containing tropical plants is attached to the Department.

Zoological Laboratory: Dr. M. B. Mirza, reader in zoology, is the chairman of the Department of Zoology.

A special feature of the Department is the museum attached to it. The museum contains all the necessary specimens for teaching work, and also a large number of rare specimens.

\section{University and Educational Intelligence}

BristoL.-Dr. H. Jones has been appointed lecturer in theoretical physies.

DubLrn.- On July 6, the following honorary degrees were conferred, among others : Sc.D. on Prof. W. L. Bragg, Langworthy professor of physics in the University of Manchester, and Prof. J. S. Haldane, honorary professor of mining and director of the Mining Research Laboratory in the University of Birmingham; Litt.D. on Sir Percy Nunn, professor of education in the University of London, and Dr. Douglas Hyde, well known for his work in connexion with Irish university education and folk-lore.

EDINBURgh.--At the graduation ceremony on June 30 , the honorary degree of doctor of laws was conferred on the Right Hon. Craigie Aitchison, M.P., Lord Advocate; Sir James Caw, formerly director of the National Galleries of Scotland; Sir Henry Dale; Prof. G. H. Hardy; Sir Alexander Houston; The Right Hon. Baron Meston, Chancellor of the University of Aberdeen; Sir Hugh Arthur Rose; Dr. J. C. Smith, formerly senior chief inspector of schools in Scotland; Dr. W. W. Tarn.

The degree of D.Litt. was conferred on Mr. G. G. Neill Wright for a thesis entitled "The Psychological Analysis of Social Structure"; and the degree of D.Sc. on Mr. J. A. Fraser Roberts for a thesis entitled "Studies on the Biology of the Sheep"; on Dr. B. P. Wiesner for a thesis entitled "Maternal Behaviour in the Rat"; and on Mr. G. B. Brook for a thesis entitled "Experimental and Clinical Studies of the Spine of the Dog".

Glasgow.-By her will, Miss B. A. Gray has bequeathed a sum of $£ 8,000$ to the University to endow a "Matthew Gray Scholarship", as a travelling scholarship for students of engineering. 